\title{
Researching the teaching and learning of multi-word expressions
}

\section{Anna Siyanova-Chanturia}

Victoria University of Wellington, New Zealand

\section{Introduction}

Recent years have seen two special issues dedicated to vocabulary published in Language Teaching Research (2015, volume 19, issue 6; 2017, volume 21, issue 1). This is a remarkable achievement for this ever growing field and the researchers concerned, and one indicating a huge amount of interest in second language (L2) vocabulary teaching and learning. The current special issue, both complementary and unique, is another important step towards solidifying vocabulary as a centrepiece of L2 pedagogy. It is complementary as, similar to the earlier special issues, it deals with vocabulary, and unique as it centres on one specific kind of it: multi-word expressions (MWEs). Despite an unprecedented interest we are witnessing with respect to MWEs as an important linguistic, psycholinguistic, cognitive and pedagogical phenomenon, few journals have published issues devoted entirely to MWEs (e.g. see Annual Review of Applied Linguistics 2012, volume 32 and The Mental Lexicon 2014, volume 9, issue 3), which makes the current pedagogy-oriented contribution a particularly timely and welcome one.

As the title of this guest editorial suggests, the research pieces included in this issue deal, directly or indirectly, with the teaching and learning of MWEs. Within this broad theme, the contributions can be said to belong to one of the following topics:

- $\quad$ knowledge of L2 MWEs (Nguyen \& Webb; Macis \& Schmitt);

- learning of L2 MWEs (Eyckmans \& Lindstromberg; Boers, Dang \& Strong; Pellicer-Sánchez);

- processing of L2 MWEs (Choi).

\section{Corresponding author:}

Anna Siyanova-Chanturia, School of Linguistics and Applied Language Studies, Victoria University of Wellington, Kelburn Parade, Wellington, 6140, New Zealand.

Email: anna.siyanova@vuw.ac.nz 
As we shall see below, each contribution focuses on a specific aspect of MWE pedagogy, is unique in the methodology adopted, and makes an original contribution to the special issue. We see a variety of contexts (English as a Foreign Language/EFL and English as a Second Language/ESL), learner backgrounds (Belgium, Chile, Korea, UK, Vietnam), types of MWEs (grammatical and lexical, verb+noun and adjective+noun collocations, and idioms), and learner proficiency levels (intermediate and advanced). Together, the special issue provides a plethora of new knowledge, on which it will be instructive to reflect. In what follows below, I first introduce the studies focusing on the knowledge of L2 MWEs, followed by the studies on the learning of MWEs: the two being common themes in vocabulary research. I then turn to a relatively novel, but rapidly growing, strand in vocabulary research: the on-line processing of MWEs.

\section{Knowledge of L2 MWEs}

Two contributions endeavoured to tap into the knowledge of MWEs. Nguyen and Webb examined (1) receptive knowledge of L2 collocation and (2) the factors that might affect this knowledge. These authors explored the relationship between the knowledge of verb+noun and adjective+ noun collocations and the knowledge of single words at different 1,000 word frequency levels. They further examined the role of five factors - node word frequency, collocation frequency, mutual information (MI) score, congruency, and part of speech - and their ability to predict receptive knowledge of collocation in a group of intermediate EFL learners in Vietnam.

A 180-item multiple-choice test was developed and used to measure receptive knowledge of the two types of collocation, with the constituent words appearing in the first three 1,000 word families (i.e. being frequent words in English). The analyses revealed that Vietnamese EFL learners had limited knowledge of collocation at the three frequency levels examined. At the second and third 1,000 word frequency level, their knowledge was below 50\%. Interestingly, although it is often argued that verb+noun collocations present greater difficulties for L2 learners than adjective+noun combination (e.g. Peters, 2016; also see Boers, Dang \& Strong, this issue), the mean receptive scores for the two types were found to be highly comparable $(45.72 \%$ for verb + noun, and $45.29 \%$ for adjective+noun). In terms of the factors affecting L2 collocational knowledge, the frequency level of the node word, rather than collocation frequency, was found to be the strongest predictor of test performance, which hints at the possibility that familiarity with a word can help learners decide which, from a set of options, is the most likely associated collocate. MI scores and congruency with the first language (L1) were also found to be significant predictors, albeit to a lesser extent. Whether the MWEs were verb+noun or adjective+noun collocations was not found to be a significant predictor, indicating that, at least at the receptive level, the two types of collocations were equally problematic for the learners in question. It will be informative for future work to focus on productive knowledge of verb+noun and adjective+noun combinations, as well as other collocation types, at different word frequency levels. Because receptive vocabulary knowledge precedes productive knowledge (e.g. Nation, 2013), and receptive learning and use is believed to be easier than productive learning and use (e.g. Ellis \& Beaton, 
1993; Nation, 2013), we cannot rule out the possibility that a different pattern will emerge from studies that use measures of productive collocation knowledge.

While the target collocations in Nguyen and Webb varied in terms of their semantics, the second contribution exploring MWE knowledge focused specifically on English figurative expressions. Macis and Schmitt examined EFL learners' knowledge of the idiomatic meaning of verb+noun and adjective+noun collocations, expressions which in the literature have traditionally been known as ambiguous idioms (e.g. Van Lancker, Canter, \& Terbeek, 1981) or as figurative idioms (e.g. Grant \& Bauer, 2004). In addition to gauging a group of learners' knowledge of figurative meanings of such expressions, the authors explored the effect of frequency, semantic transparency, the learners' year at university (as a proxy of their L2 proficiency) and L2 use on this knowledge. A 30-item meaning-recall test was administered to a group of advanced English learners at a Chilean university, followed by a background questionnaire asking participants about their language learning experiences. It is commendable that in their analysis, Macis and Schmitt opted for linear mixed-effects modelling, rather than the more traditional ANOVAs or their non-parametric equivalents. Linear mixed-effects modelling is rapidly becoming mainstream in the field of applied linguistics, because it includes both participants and items as random effects and does not necessitate running separate analyses with participants $(F 1)$ and items $(F 2)$ as random variables (e.g. Baayen, Davidson, \& Bates, 2008).

The analysis showed that despite their relatively high English language proficiency, the Chilean learners knew 'only about $33 \%$ of the target figurative collocation meanings' (p. 331). To put it differently, the learners knew only $33 \%$ of the idioms investigated. At first sight, this confirms that the pace of uptake of L2 idioms tends to be slow (e.g. Abel, 2003; Irujo, 1986; Kecskés, 2000) due to their often non-transparent meanings and relatively low frequencies of use. However, as the authors report, frequency was not found to be a significant predictor of idiom knowledge, and neither was semantic transparency. On the contrary, what did affect learners' knowledge of idiomatic expressions were a year at university and experience with English outside the classroom (e.g. through reading, watching TV, etc.). If frequency in a large reference corpus was not a significant factor that affected these learners' knowledge (or lack thereof) of L2 idiomatic expressions, then the question arises as to what kind of input - in terms of authenticity and representativeness of English figurative language - these learners were exposed to through their university studies and their activities outside of classroom. These are intriguing findings that beg for further investigation and replication.

\section{Learning of L2 MWEs}

Macis and Schmitt's study is a testament to the limited L2 knowledge of idiomatic expressions and the challenges that both teachers and learners face when dealing with figurativeness in language. The contribution by Eyckmans and Lindstromberg also concerns idioms, but focuses on learners' recall of the lexical makeup of such expressions. More specifically, Eyckmans and Lindstromberg investigated the role of phonological similarity - alliteration and assonance - in the intentional learning of previously unknown English idioms. A group of advanced learners of English (L1 Dutch) was exposed to a 
treatment that helped learners notice and attend to alliteration (e.g. fast and furious) and assonance (e.g. jump the gun ), while a comparison group was not. In addition, these researchers were interested in relatively durable learning effects, rather than immediate but short-lived learning gains, and hence a delayed post-test was administered one week after the treatment.

The results suggested that phonologically similar idioms were learnt better than control items, following a treatment that raised learners' awareness of and directed their attention to sound-repeating patterns. Unexpectedly, in the absence of such treatment, control items showed significantly superior learning gains compared to the soundrepeating idioms. It is noteworthy, however, that the target idioms (exhibiting assonance or alliteration) and the control items (exhibiting none of the two) were not necessarily optimally matched for compositionality (also known as analysability, e.g. Gibbs, Nayak, \& Cutting, 1989). In the case of decomposable idioms, their individual components contribute to the idiom's overall figurative meaning (e.g. pop the question), while for nondecomposable idioms this is not the case (e.g. kick the bucket). If the set of control items included a greater number of decomposable idioms, this could possibly explain why, in the absence of the treatment which engaged learners with the said phonological patterns, these stood a better chance of being remembered. Future research should be able to shed further light on the learning of L2 idioms with and without phonological similarity, more systematically controlling for the (admittedly wide range of) factors known to affect idiom learning (compositionality, transparency, congruency with L1, and so on; see Cieślicka, 2013a, 2013b).

Another contribution focusing on intentional learning of MWEs is that by Boers, Dang and Strong. These authors sought to replicate an earlier study by Boers, Demecheleer, Coxhead and Webb (2014) that tested the effectiveness of phrase-focused exercises commonly found in English textbooks. It is noted that despite MWEs figuring prominently in many EFL and ESL textbooks, little research has been conducted to test the effectiveness of exercises targeting strings above word level. In the replication, Boers et al. addressed some of the limitations of the earlier study. For example, the sample size was increased, the pre-test was dropped as it could have influenced the students' performance, focus on meaning was added on top of focus on form, and, finally, the choice of exercise formats was better justified. The aim of the replication was to compare the effectiveness of three exercise formats on the learning of English verb+noun collocations by intermediate EFL learners in Vietnam: (1) select the correct verb from a list, (2) provide the correct verb with the first letter given, and (3) select the intact phrase from a list. The test phase took place two weeks after the treatment and targeted both form and meaning recall.

By and large, the main finding of this replication study offered support to Boers et al. (2014), in that the most beneficial, in terms of verb+noun collocation form and meaning recall, exercise type was the format that involved selecting an entire phrase from a list. In addition, akin to Boers et al. (2014), the results of the current study suggested that breaking down a conventional phrase into its constituents and asking students to select the verb from a list was likely to generate wrong verb+noun associations. Nevertheless, as pointed out by the authors, more empirical work is needed to further solidify and extend the present findings. For example, it would be interesting to focus on other 
collocation types, investigate the effect of repetition on the learning gains across the various exercise formats, as well as look at long-term learning gains (e.g. a month or two post treatment).

Boers et al. argued for an experimental design that avoids pre-testing. While these authors achieved this by using a group of learners comparable in their characteristics to the actual participant population to test and select the target items, Pellicer-Sánchez opted for the use of pseudowords. Similar to Eyckmans and Lindstromberg and Boers, et al., Pellicer-Sánchez focused on the learning of MWEs. Unlike them, however, she focused on incidental learning, more specifically intermediate ESL learners' acquisition of adjective+ + pseudoword collocations from reading. In addition, the role of frequency of exposure was examined; participants were exposed to the target adjective+pseudoword collocations (e.g. small berrow 'small bowl') either four or eight times in a story context.

In line with earlier research, the results offered support to the effectiveness of reading for the incidental learning of both single words (pseudoword) and collocations. As expected, learners were more successful in post-tests at recognizing the collocate form $(50.5 \%)$ than recalling it $(11 \%)$. The author reports that not only were the receptive aspects of the form of collocation easier to acquire, but the learners were also more certain about this kind of knowledge. Also noteworthy is that the frequency of occurrence (four vs. eight times) of the target collocations was not found to be a statistically significant factor in the acquisition of MWEs in this study (unlike what was found in an earlier study by Webb, Newton \& Chang, 2013). The author notes that the results reported may be specific to the kind of collocation investigated-adjective + pseudoword - and hence further research needs to be conducted on other types of collocations, and MWEs more generally. Interestingly, Pellicer-Sánchez considers the use of pseudowords a limitation of her study. On the one hand, the use of carefully chosen pseudowords might be superior to other options, such as including a pre-test to identify unknown items, or testing candidate items with an unrelated learner group comparable in proficiency to the target participant group, or using low frequency words that are unlikely to be known to the participants. ${ }^{1}$ On the other hand, many collocations consist of familiar words, and it is this familiarity that may reduce the attention paid to these word combinations. A pseudoword is by definition unfamiliar and may thus attract more attention (e.g. Godfroid, Boers, \& Housen, 2013). In addition, in some learning contexts (e.g. a language classroom), it may be considered inappropriate, and even unethical, to use pseudowords. In sum, the jury is still out as to which of the above options is best, and the decision is likely to depend on the learning situation, as well as the study design, aims and objectives.

\section{Processing of L2 MWEs}

The final contribution to the special issue, by Choi, centres both on the processing and learning of MWEs. However, because of its strong focus on on-line processing, ${ }^{2}$ I will cover it under the above heading and separate from the other contributions. Although I have left this contribution till the end of the guest editorial, it is a piece to be excited about, not least because it is the first study employing eye movement data to be published 
in Language Teaching Research, and is a prime example of how psycholinguistic methods can be fruitfully used in pedagogically-oriented research.

Using an eye-tracking paradigm, Choi investigated the processing and learning of English collocations from reading by Korean learners. A key focus of the study was on the role of textual enhancement (bold typeface) in the learning of MWEs, and the effect it may have on the recall of unenhanced text. There is a growing body of research on the role of textual enhancement on MWE learning (for a review see, for example, Boers, Demecheleer, $\mathrm{He}$, et al., 2016). However, the present study is one of the relatively few ones to use a psycholinguistic technique to investigate attentional mechanisms involved in such learning, by means of examining the processing patterns, as well as analysing post-experiment recall. In addition, it is commendable that two types of collocations were looked at: lexical (e.g. wide awake), which are most commonly investigated in MWE research, and grammatical (e.g. on week-ends), which are far less commonly studied. Intermediate EFL learners read a text containing 14 target collocations - half saw the version with enhanced collocations and the other half with unenhanced collocations (control group) - while their eye movements were recorded. It is noteworthy that two eye-tacking measures were used: total reading time and fixation count, of which only the former is a measure of processing time (e.g. Rayner, 1998, 2009). Generally, given that the eye-movement technique allows for a wealth of data to be analysed, it is advisable for a minimum of three or four eye-tracking measures to be examined (of which two or three are measures of processing time). As Rayner (1998) notes, any single measure is 'a pale reflection of the reality of cognitive processing' ( $\mathrm{p}$. 377). It is further desirable to look at a variety of measures known to reflect various stages of language processing (e.g. early/mid and late measures; e.g. Carrol \& Conklin, 2015; Pellicer-Sánchez, 2016; Siyanova-Chanturia, Conklin, \& Schmitt, 2011; SiyanovaChanturia, Conklin, \& van Heuven, 2011; Vilkaité, 2016; for a review of eye movements in the context of MWEs, see Roberts \& Siyanova-Chanturia, 2013; Siyanova-Chanturia, 2013). Still, given the scarcity of pedagogically-oriented vocabulary research employing eye movements, the present contribution is a significant one.

The analysis of the eye-tracking and recall data suggested that the group exposed to enhanced text spent more time processing target collocations and, as a result, performed better on a post-experiment collocation test compared to the control group. This finding, although interesting, is unsurprising and was expected. What is, perhaps, more interesting is that the enhanced condition group was found to be less successful than the control group when it came to recalling unenhanced text. That is, a trade-off effect was observed between enhanced collocation learning and recall of unenhanced text. The author concluded that this trade-off was likely to be due to additional cognitive resources being allocated to vocabulary items unknown to the reader. Although Choi included both lexical and grammatical collocations, the items were too few to be analysed separately. It would be very interesting, indeed, to investigate the processing and learning of lexical versus grammatical collocations, as well as to analyse the role of textual enhancement using eye movements and a battery of post-experiment tests.

\section{Conclusions}

I have briefly reviewed six contributions that focus on MWEs from three different but complementary perspectives: knowledge, learning and processing of strings above 
word level in a second language. These studies make an original contribution to the field and will undoubtedly be of interest to vocabulary enthusiasts. These studies are enviably diverse in their aims and objectives, kinds of MWEs, learner profiles, methods and analyses adopted. Before I conclude the guest editorial, however, some final considerations for future research need to be noted, if we are to fully understand the multifarious phenomenon that MWEs are. First, it is striking that the six contributions all focus on English MWEs, which is rather representative of the field in general (with some notable exceptions; for example, Peters, 2012; Stengers, Boers, Housen, \& Eyckmans, 2011). Although, as noted by Siyanova-Chanturia and Spina (2015), there are no reasons to believe that languages differ in the ways in which MWEs are acquired and processed by second language learners, I believe it is important for the field that a range of L2s are represented alongside English (an argument also put forward by Ortega, 2009). Second, this special issue and Choi's contribution, in particular, allows for a strong case to be made for greater interdisciplinarity in the field. While the many and varied issues associated with MWE processing have recently been getting a lot of attention (for example, see Siyanova-Chanturia, 2013, 2015; Siyanova-Chanturia \& Martinez, 2015), more pedagogically-oriented research is yet to benefit from this interaction. Finally, it is commendable to see Language Teaching Research welcome replication studies (e.g. Boers et al., this issue). As noted by Porte (2012), replication provides essential methodological support for the theory tested, and is thus an integral part of the scientific process. It is my hope that this special issue will pave the way for more replication studies in Language Teaching Research and in the field in general.

\section{Funding}

The author(s) received no financial support for the research, authorship, and/or publication of this article.

\section{Notes}

1 In terms of using low frequency words, it is noteworthy that such items may be known to some of the participants (unless a pre-test is conducted to refute this possibility); and, if these words are completely unknown, they are, in fact, no different from pseudowords.

2 On-line processing is processing happening in real time. In such studies, reading, reaction times, and/or brain activity are recorded while participants perform a task.

\section{References}

Abel, B. (2003). English idioms in the first language and second language lexicon: A dual representation approach. Second Language Research, 19, 329-358.

Baayen, R.H., Davidson, D.J., \& Bates, D.M. (2008). Mixed-effects modeling with crossed random effects for subjects and items. Journal of Memory and Language, 59, 390-412.

Boers, F., Demecheleer, M., Coxhead, A., \& Webb, S. (2014). Gauging the effects of exercises on verb-noun collocations. Language Teaching Research, 18, 54-74.

Boers, F., Demecheleer, M., He, L., Deconinck, J., Stengers, H., \& Eyckmans, J. (2016). Typographic enhancement of multiword units in second language text. International Journal of Applied Linguistics. Electronic publication ahead of print version. Published online: 25 April 2016 (doi: 10.1111/ijal.12141). 
Carrol, G., \& Conklin, K. (2015). Cross language priming extends to formulaic units: Evidence from eye tracking suggests that this idea 'has legs'. Bilingualism: Language and Cognition, 20, 299-317.

Cieślicka, A. (2013a). Do nonnative language speakers chew the fat and spill the beans with different brain hemispheres? Investigating idiom decomposability with the divided visual field paradigm. Journal of Psycholinguistic Research, 42, 475-503.

Cieślicka, A. (2013b). Second language learners' processing of idiomatic expressions: Does compositionality matter? In K. Droździal-Szelest, \& M. Pawlak (Eds.). Psycholinguistic and sociolinguistic perspectives on second language learning and teaching. Second Language Learning and Teaching. Berlin, Heidelberg: Springer, pp. 115-136.

Ellis, N.C., \& Beaton, A. (1993). Factors affecting foreign language vocabulary: Imagery keyword mediators and phonological short-term memory. Quarterly Journal of Experimental Psychology, 46A, 533-538.

Gibbs, R., Nayak, N., \& Cutting, C. (1989). How to kick the bucket and not decompose: Analyzability and idiom processing. Journal of Memory and Language, 28, 576-593.

Godfroid, A., Boers, F., \& Housen, A. (2013). An eye for words: Gauging the role of attention in L2 vocabulary acquisition by means of eye-tracking. Studies in Second Language Acquisition, $35,483-517$.

Grant, L., \& Bauer, L. (2004). Criteria for redefining idioms: Are we barking up the wrong tree? Applied Linguistics, 25, 38-61.

Irujo, S. (1986). Don't put your leg in your mouth: Transfer in the acquisition of idioms in a second language. TESOL Quarterly, 20, 287-304.

Kecskés, I. (2000). A cognitive-pragmatic approach to situation-bound utterances. Journal of Pragmatics, 32, 605-625.

Nation, I.S.P. (2013). Learning vocabulary in another language. 2nd edition. Cambridge: Cambridge University Press.

Ortega, L. (2009). Understanding second language acquisition. London: Hodder.

Pellicer-Sánchez, A. (2016). Incidental L2 vocabulary acquisition from and while reading: An eye tracking study. Studies in Second Language Acquisition, 38, 97-130.

Peters, E. (2012). Learning German formulaic sequences: The effect of two attention-drawing techniques. Language Learning Journal, 40, 65-79.

Peters, E. (2016). The learning burden of collocations: The role of interlexical and intralexical factors. Language Teaching Research, 20, 113-138.

Porte, G. (Ed.) (2012). Replication research in applied linguistics. Cambridge: Cambridge University Press.

Rayner, K. (1998). Eye movements in reading and information processing: 20 years of research. Psychological Bulletin, 124, 372-422.

Rayner, K. (2009). The 35th Sir Frederick Bartlett Lecture: Eye movements and attention during reading, scene perception, and visual search. Quarterly Journal of Experimental Psychology, $62,1457-1506$.

Roberts, L., \& Siyanova-Chanturia, A. (2013). Using eye-tracking to investigate topics in L2 acquisition and L2 sentence and discourse processing. Studies in Second Language Acquisition, 35, 213-235.

Siyanova-Chanturia, A. (2013). Eye-tracking and ERPs in multi-word expression research: A state-of-the-art review of the method and findings. The Mental Lexicon, 8, 245-268.

Siyanova-Chanturia, A. (2015). On the 'holistic' nature of formulaic language. Corpus Linguistics and Linguistic Theory, 11, 285-301.

Siyanova-Chanturia, A., \& Martinez, R. (2015). The idiom principle revisited. Applied Linguistics, $36,549-569$. 
Siyanova-Chanturia, A., \& Spina, S. (2015). Investigation of native speaker and second language learner intuition of collocation frequency. Language Learning, 65, 533-562.

Siyanova-Chanturia, A., Conklin, K., \& Schmitt, N. (2011). Adding more fuel to the fire: An eye-tracking study of idiom processing by native and nonnative speakers. Second Language Research, 27, 251-272.

Siyanova-Chanturia, A., Conklin, K., \& van Heuven, W. (2011). Seeing a phrase 'time and again' matters: The role of phrasal frequency in the processing of multi-word sequences. Journal of Experimental Psychology: Language, Memory and Cognition, 37, 776-784.

Stengers, H., Boers, F., Housen, A., \& Eyckmans, J. (2011). Formulaic sequences and L2 oral proficiency: Does the type of target language influence the association? International Review of Applied Linguistics, 49, 321-343.

Van Lancker, D., Canter, G., \& Terbeek, D. (1981). Disambiguation of ditropic sentences: Acoustic and phonetic cues. Journal of Speech and Hearing Research, 24, 330-335.

Vilkaité, L. (2016). Are nonadjacent collocations processed faster? Journal of Experimental Psychology: Learning, Memory and Cognition, 42, 1632-1642.

Webb, S., Newton, J., \& Chang, A.C.-S. (2013). Incidental learning of collocation. Language Learning, 63, 91-120. 